\title{
Participation in and adherence to physical exercise after completion of primary cancer treatment
}

\author{
Caroline S. Kampshoff' ${ }^{1}$, Willem van Mechelen ${ }^{1}$, Goof Schep ${ }^{3}$, Marten R. Nijziel' ${ }^{4}$ Lenja Witlox², Lisa Bosman²,
} Mai J. M. Chinapaw ${ }^{1}$, Johannes Brug ${ }^{2}$ and Laurien M. Buffart ${ }^{2^{*}}$

\begin{abstract}
Background: The purpose of this study was to identify demographic, clinical, psychosocial, physical and environmental factors that are associated with participation in and adherence to a combined resistance and endurance exercise program among cancer survivors, shortly after completion of primary cancer treatment. Data from the randomized controlled Resistance and Endurance exercise After ChemoTherapy (REACT) study were used for this study.

Methods: The participants of the REACT study were randomly allocated to either a high intensity (HI) or lowto-moderate intensity (LMI) exercise program. Patients' participation rate was defined as the cancer survivors' decision to participate in the REACT study. Exercise adherence reflected participants' attendance to the scheduled exercise sessions and their compliance to the prescribed exercises. High session attendance rates were defined as attending at least $80 \%$ of the sessions. High compliance rates were defined as performing at least of $90 \%$ of the prescribed exercise across all sessions. Correlates of exercise adherence were studied separately for $\mathrm{HI}$ and LMI exercise. Demographic, clinical, and physical factors were assessed using self-reported questionnaires. Relevant clinical information was extracted from medical records. Multivariable logistic regression analyses were applied to identify correlates that were significantly associated with participation, high session attendance, high compliance with resistance and high compliance with endurance exercises.
\end{abstract}

Results: Participants were more likely to have higher education, be non-smokers, have lower psychological distress, higher outcome expectations, and perceive more exercise barriers than non-participants. In HI exercise, higher self-efficacy was significantly associated with high session attendance and high compliance with endurance exercises, and lower psychological distress was significantly associated with high compliance with resistance exercises. In LMI exercise, being a non-smoker was significantly associated with high compliance with resistance exercises and higher BMI was significantly associated with high compliance with resistance and endurance exercises. Furthermore, breast cancer survivors were less likely to report high compliance with resistance and endurance exercises in LMI exercise compared to survivors of other types of cancer. The discriminative ability of the multivariable models ranged from 0.62 to 0.75 .

Conclusion: Several demographic, clinical and psychosocial factors were associated with participation in and adherence to exercise among cancer survivors. Psychosocial factors were more strongly associated with adherence in $\mathrm{HI}$ than LMl exercise.

Trial registration: This study was registered at the Netherlands Trial Register [NTR2153] on the $5^{\text {th }}$ of January 2010.

Keywords: Cancer survivors, Exercise, Participation, Exercise adherence, Session attendance, Compliance, Correlates

\footnotetext{
* Correspondence: l.buffart@vumc.nl

${ }^{2}$ Department of Epidemiology and Biostatistics and the EMGO Institute for

Health and Care Research, VU University Medical Center, De Boelelaan 1089a,

1081 HV Amsterdam, The Netherlands

Full list of author information is available at the end of the article
}

(c) 2016 The Author(s). Open Access This article is distributed under the terms of the Creative Commons Attribution 4.0 International License (http://creativecommons.org/licenses/by/4.0/), which permits unrestricted use, distribution, and reproduction in any medium, provided you give appropriate credit to the original author(s) and the source, provide a link to the Creative Commons license, and indicate if changes were made. The Creative Commons Public Domain Dedication waiver (http://creativecommons.org/publicdomain/zero/1.0/) applies to the data made available in this article, unless otherwise stated. 


\section{Background}

Supervised exercise programs following cancer diagnosis show significant and clinically relevant beneficial effects on cardiorespiratory fitness [1], general and physical fatigue [2] and quality of life (QoL) [3]. More specifically, exercise can improve cancer survivors' cardiorespiratory fitness, thereby reducing fatigue and improve global QoL and physical function [4]. In addition, observational studies have reported positive associations of physical activity [5] and fitness [6] with cancer-free and overall survival, yet, randomized controlled trials (RCTs) need to establish causality.

The success of RCTs evaluating exercise programs depends largely on patients' participation and exercise adherence rates. Patients' participation rate reflects the decision by cancer survivors whether or not to participate in a randomized controlled trial evaluating exercise interventions. Exercise adherence reflects participants' session attendance rates and their compliance to the prescribed exercises. A better understanding of the modifiable and unmodifiable correlates that are associated with participation in and adherence to exercise interventions may inform future interventions and facilitate successful implementation of exercise programs among cancer survivors. Modifiable correlates (e.g., psychosocial) provide insights into intervention target components via which improvements in participation or adherence might be achieved. Unmodifiable correlates, such as demographics (e.g., age) or clinical variables (e.g., treatment type) indicate which subgroups of patients are most at risk for non-participation or low exercise adherence rates and can thus help to identify relevant target populations for intervention.

Correlates of participation in exercise trials during primary cancer treatment have been investigated by two previous trials $[7,8]$ and both studies reported that participants who perceived higher levels of fatigue were less likely to participate in the exercise trials. Furthermore, minimizing practical barriers to participation such as travel distances to practices and flexible training schedules were suggested as promising strategies to enhance participation in forthcoming studies [7, 8]. However, correlates of participation in exercise trials after completion of primary cancer treatment have not been studied yet, and may differ from those during primary cancer treatment.

In a recent systematic review, we identified correlates of exercise adherence among cancer survivors [9], and found exercise history to be significantly associated with exercise adherence. Other important demographic, clinical, psychosocial and environmental correlates of exercise adherence could not be distinguished due to the limited number of studies, or the inconsistency of findings across the reviewed manuscripts. Moreover, the definition of exercise adherence varied across the reviewed studies. Some studies exclusively focused on session attendance rate, while other studies also incorporated a measure on compliance. Therefore, more research is warranted.

The current study aimed to identify demographic, clinical, psychosocial, physical and environmental factors that are associated with participation in an exercise program and exercise adherence among cancer survivors, shortly after completion of primary cancer treatment. We used data of the Resistance and Endurance exercise After ChemoTherapy (REACT) study [10], a RCT that evaluated the effectiveness of a high intensity (HI) and low-tomoderate intensity (LMI) exercise compared to a waiting list control (WLC) group shortly after completion of primary cancer treatment on physical fitness, fatigue and health-related quality of life (HRQoL). We found that HI and LMI exercise significantly improved cardiovascular fitness, reduced fatigue and improved quality of life [11].

\section{Methods}

Detailed procedures of the REACT study have been reported elsewhere [11]. Briefly, the REACT study was a multicenter RCT in which 277 cancer survivors were randomized into three study arms: HI exercise, LMI exercise, and a WLC group. Between 2011 and 2013, patients were recruited from 9 hospitals in the Netherlands. Patients aged $\geq 18$ years with histologically confirmed breast, colon, ovarian, cervix or testis cancer, or lymphomas with no indication of recurrent or progressive disease, who had completed ((neo-) adjuvant) chemotherapy were eligible. Patients were excluded if they were unable to perform basic physical activity, had cognitive disorders, severe emotional instability, comorbidities that might hamper capacity of carrying out HI exercise, or were unable to understand and read the Dutch language. This study was approved by the Medical Ethics Committee of the VU University Medical Centre [2011/240] and the local ethical boards of all participating hospitals.

\section{(Non-)participation}

Patients who were willing to participate were invited for baseline measurements, 4-6 weeks after completion of primary cancer treatment. After baseline measurements, participants were stratified by cancer type and hospital, and randomly assigned to one of the three study arms. HI and LMI groups started with their 12-weeks exercise program directly after randomization (i.e., direct start). Participants from the WLC group were also randomly allocated to HI or LMI exercise. However, they started exercising 12 weeks later. Patients who chose not to participate (i.e., non-participants) were invited to complete a one-time survey that was similar in content and timing to the baseline questionnaire of the REACT participants. Written informed consent was obtained from both non-participants and participants, including permission to extract relevant 
information from their medical records. Finally, from patients who chose to refrain from any participation, only age, gender and cancer type were documented.

\section{Exercise interventions}

Full details of the 12-week HI and LMI programs have been described previously [10]. In short, both interventions included two one-hour supervised resistance and endurance exercise sessions per week and were identical with respect to exercise frequency, type, and duration, and differed only in exercise intensity (Table 1). Both exercise programs included six resistance exercises targeting large muscle groups with a frequency of two sets of ten repetitions. Workload per exercise was defined by an indirect one repetition maximum (1-RM) measurement. Furthermore, both programs included two types of endurance interval exercises, aiming to maximize improvements in cardiorespiratory fitness. In the first four weeks patients cycled 2x8 min with alternating workloads. Workloads were defined by the maximum short exercise capacity (MSEC) estimated by the steep ramp test. From the fifth week onwards, one additional endurance interval session was added, substituting eight minutes of cycling. This interval session consisted of three times five minutes cycling at a constant workload. Here, the workload was defined by the heart rate reserve (HRR), using the Karvonen formula. Twenty-one local physiotherapists supervised all training sessions. In the Netherlands, people are generally used to short travel distances to their health care providers and therefore patients trained at local physiotherapists practices close to the patients' homes. The availability of flexible training hours and the possibility to join a rehabilitation group differed per practice. Furthermore, the start of the exercise programs was linked to the time point of completion of the primary cancer treatment of the individual cancer survivor. Consequently, the training hours and the availability of group sessions varied.

\section{Adherence}

Adherence was defined as attendance to the prescribed number of sessions and compliance with the prescribed intensity, frequency and duration of the prescribed resistance and endurance exercises $[12,13]$. Both session attendance rates and compliance rates were retrieved from exercise logs completed by the physiotherapists. Session attendance was defined as the number of supervised exercise sessions attended, divided by the number of supervised exercise sessions offered. Compliance with resistance exercises was defined in terms of intensity and volume (Table 2), in which compliance with the intensity of the resistance exercises was calculated by the performed training load, divided by the prescribed training load and compliance with the volume of the resistance exercises was calculated by the performed number of repetitions, divided by the prescribed number of repetitions. The average value of compliance with intensity and volume provided the overall measure for compliance with the resistance exercises. Compliance with endurance exercises was defined as exercise duration (in minutes), divided by the prescribed exercise duration (Table 2). The average of this parameter provided the overall measure for compliance with the endurance exercises. Next, the normality assumption was tested for session attendance, compliance with resistance training, and compliance with endurance training. Since they were skewed, and to facilitate clinically meaningful interpretation, we dichotomized adherence outcome variables based on clinically-relevant cut-off points. In line with previous studies, high session attendance was defined as attending at least $80 \%$ of the sessions [14]. We defined high compliance rates as performing at least $90 \%$ of the resistance and endurance exercises according to the prescribed dosage. This cut-off point of $90 \%$ allowed some deviation due to the rounded weights and settings of the local training equipment, while maintaining a sufficient distinction between HI and LMI exercise.

\section{Assessment of correlates}

Demographic data were collected using a self-report questionnaire and included age at baseline (in years), gender $(0=$ male; $1=$ female $)$, marital status $(0=$ no partner; $1=$ married or de facto $)$, education $(0=$ low/intermediate;

Table 1 Exercise intensities of the $\mathrm{HI}$ and LMI resistance and endurance exercise programs

\begin{tabular}{|c|c|c|c|c|}
\hline & $\begin{array}{l}\text { Resistance exercises (1-RM) } \\
\text { (10 repetitions in } 2 \text { series } \\
\text { of } 6 \text { exercises targeting the } \\
\text { large muscle groups) }\end{array}$ & $\begin{array}{l}\text { Endurance interval exercises } \\
\text { Part A (MSEC) } \\
\text { (8 min alternating workload) }\end{array}$ & $\begin{array}{l}\text { Endurance interval exercises } \\
\text { Part B (HRR) })^{a} \\
(3 \times 5 \text { min constant workload })\end{array}$ & Counseling \\
\hline $\begin{array}{l}\text { High intensity }(\mathrm{HI}) \\
\text { exercise }^{b}\end{array}$ & $70-85 \%$ & $30 / 65 \%$ & $\geq 80 \%$ & \multirow{2}{*}{$\begin{array}{l}\text { Participants were encouraged } \\
\text { to start or maintain a physically } \\
\text { active lifestyle in addition to } \\
\text { the supervised exercise sessions. }\end{array}$} \\
\hline $\begin{array}{l}\text { Low-to-moderate intensity } \\
\text { (LMI) exercise }\end{array}$ & $40-55 \%$ & $30 / 45 \%$ & $40-50 \%$ & \\
\hline
\end{tabular}

Abbreviations: 1-RM one repetition maximum, MSEC maximum short exercise capacity, $H R R$ heart rate reserve, $H I$ high intensity exercise, $L M I$ low-to-moderate intensity exercise

${ }^{a}$ Every four weeks (week 1, 5 and 9), the physiotherapist evaluated training progress, and adjusted the workload accordingly. ${ }^{\mathrm{b}}$ Exercises were accompanied with BORG scores and heart rate monitors to guide the physiotherapists. In the occasion that the training intensity seemed too high or too low, the 1-RM, MSEC or HRR were reassessed 
Table 2 Outcome measures of compliance to the prescribed exercises

\begin{tabular}{|c|c|c|}
\hline \multicolumn{3}{|l|}{ Compliance } \\
\hline Resistance exercises & & Endurance interval \\
\hline Intensity & Volume & Duration \\
\hline $\begin{array}{l}\text { Used load } \\
\text { Prescribed load }\end{array} \times 100 \%$ & $\frac{\text { Performed repetitions }}{\text { Prescribed repetitions }} \times 100 \%$ & $\frac{\text { Performed duration }}{\text { Prescribed duration }} \times 100 \%$ \\
\hline
\end{tabular}

a Load in kilograms, ${ }^{b}$ time in minutes

$1=$ high $)$, employment status $(0=$ no paid employment; 1 = paid employment), smoking status $(0=$ non-smoker; $1=$ smoker $)$ and sport history $(0=$ no; 1 =yes $)$. Furthermore, participants' travel distance to the exercise program (in kilometres) was calculated based on zip codes of the patient's home and location of training facility.

Clinical information was retrieved from medical records and included cancer type ( $0=$ breast cancer; $1=$ other (i.e., colon, ovarian, cervix or testis cancer, or lymphomas)), stage of disease $(0=$ stage I-II, $1=$ stage III-IV), previous treatment with surgery $(0=$ no; $1=$ yes $)$, radiation therapy $(0=$ no; $1=$ yes $)$, immunotherapy $(0=$ no; $1=$ yes $)$, hor mone therapy $(0=$ no; $1=$ yes $)$, and two or more of the following comorbidities $(0=$ no; $1=$ yes $)$ including heart disease, lung disease, diseases of the digestive system, diseases of the nervous system, endocrine disease, mental disorder, rheumatism or arthritis, or chronic pain [15]. In addition, body weight of the REACT participants was measured to the nearest $0.1 \mathrm{~kg}$ on a digital scale, with light clothes on and no shoes. Body height was measured to the nearest $0.1 \mathrm{~cm}$ without shoes. Body mass index (BMI) was calculated from the measured body weight and height accordingly.

Patient-reported outcomes have been reported elsewhere [16] and included general fatigue (subscale of the Multidimensional Fatigue Inventory (MFI) [17]), global quality of life (subscale of the European Organisation Research and Treatment of Cancer - Quality of Life Questionnaire C30 (EORTC QLQ C-30) [18]), psychological distress (Hospital Anxiety and Depression Scale (HADS) [19]) and self-reported physical activity using the Physical Activity Scale for the Elderly questionnaire (PASE) [20].

Patient-reported behavioral and attitudinal factors towards exercise included a series of questions that were based on health behavior theories, in particular the Theory of Planned Behavior [21]. Current attitude towards exercise participation was measured by one item 'In my opinion regular exercise is.' rated on 5-point Likert scale (1 = very bad to $5=$ very good) [21]. Barriers to exercise behavior (Cronbach's $\alpha=0.85$ ) were measured using 18 items (e.g., my disease, insufficient motivation, lack of energy), rated on 5 -point Likert scale $(1=$ never to $5=$ very often $)$ $[21,22]$. Outcome expectations regarding exercise participation (Cronbach's $\alpha=0.91$ ) included 12 items (e.g., increase my health, feel better about myself, and be more physically fit), rated on a 5 -point Likert scale ( $1=$ strongly disagree to $5=$ strongly agree) [21, 22]. Exercise self-efficacy (Cronbach's $\alpha=0.83$ ) was assessed with the following question 'How confident are you that you will be physically active in the following situations', including feeling tired, bad mood, do not have the time, on vacation, and, want to be active outside, but bad weather, rated on a 10 -point Likert scale $(1=$ absolutely no confidence, $10=$ completely confident) [23]. Social support for exercise (Cronbach's $\alpha=0.92$ ) was assessed using the statement: 'The following people are supportive of my regular PA', followed by: family, friends, and other cancer patients, rated on a 5 -point Likert scale $(1=$ strongly disagree to $5=$ strongly agree) [24]. Mean scores were calculated for potential correlates that comprised more than one item. After that, all factors were linearly transformed to a 0-100 scale. Exercise stage was measured using the response options derived from the Transtheoretical Model [25]: (1) no intention to exercise; (2) intention to exercise; (3) irregular exercise; (4) started exercising 30 min a day in last 6 months; or (5) exercising $30 \mathrm{~min}$ a day for longer than 6 months, that were dichotomized into non-exerciser (response options 1-3) and exerciser (response options 4-5).

\section{Statistical analyses}

The statistical analyses were performed using IBM SPSS Statistics (SPSS Inc., Evanston, IL, version 22.0). Descriptive statistics (mean and standard deviations (SD)) were calculated for all outcome variables. Data on BMI and travel distance to the exercise program for the non-participants were not available due to trial logistics. Correlations between all potential correlates were checked for multicollinearity $(r \geq 0.60)$. Multicollinearity was present between cancer type and gender. Because cancer type was most strongly associated with exercise adherence, this variable was included in the model instead of gender. Differences in session attendance rates and compliance rates between $\mathrm{HI}$ and LMI exercise were tested using chi-square tests. To examine whether correlates of exercise adherence differed between HI and LMI exercise groups, we added an interaction term of the correlate with the interventions into a regression model, separately for each correlate. As significant interaction terms were found for education, cancer type, self-efficacy, and psychological distress, we performed stratified analyses for HI and LMI. All analyses on exercise adherence were performed according to an intention-to-treat principle.

Univariable and multivariable logistic regression analyses were conducted to identify factors that were significantly correlated with participation and exercise adherence. Separate multivariable logistic regression analyses with a forward selection procedure were carried out for each 
outcome variable: participation, high session attendance and high compliance with the resistance and endurance exercises. By default, timing of intervention (i.e., direct start or WLC group) was retained as covariate in the univariable and multivariable models of exercise adherence. First the independent variables with a $p$-value $\leq 0.25$ in the univariable analyses were selected for further analyses. After that, a multivariable stepwise forward selection procedure was undertaken by identifying the correlates that was most strongly associated with the dependent variable. Subsequently, the next strongest related correlate was then selected after controlling for the first correlate. Only variables with a $p$-value of $\leq 0.05$ were retained in the final multivariable model. The regression coefficients $(\beta)$ and odds ratio (OR) with $95 \%$ CI were reported accordingly. In addition, the model fit was evaluated by the area under the receiver operating characteristic curve (AUC) with $95 \%$ CI.

\section{Results}

In total, 277 out of 757 eligible patients (37\%) participated. Furthermore, 179 patients $(24 \%)$ did not participate in the trial, but completed the one-time survey (i.e., nonparticipants). Self-reported reasons for non-participation were having too many things on one's mind $(n=72)$, already exercising $(n=30)$, not wanting to be randomized $(n=20)$, and not interested to participate in a clinical trial $(n=13)$. For 44 non-participants the reason of non-participation was unknown. Baseline demographic, clinical, psychosocial and physical characteristics of the participants and non-participants are presented in Table 3. $90 \%$ of the participants and non-participants underwent surgery to treat cancer, revealing very little variability within our population. Therefore, we omitted surgery as a potential correlate for participation and exercise adherence from the multivariable regression analyses.

High session attendance was found in $76 \%$ and $67 \%$ of the participants in HI and LMI groups respectively $(p=0.10)$. High compliance with resistance exercises was found in $69 \%$ of the participants in HI and in $67 \%$ of participants in LMI $(p=0.80)$. High compliance with endurance exercises was found in $47 \%$ of the participants in $\mathrm{HI}$ and in $42 \%$ of the participants in LMI $(p=0.40)$.

\section{Correlates of participation}

The results of the univariable and multivariable logistic regression analyses are presented in Table 4. The multivariable regression model showed that participants were more likely to have higher education, $(\mathrm{OR}=1.79,95 \% \mathrm{CI}$ : 1.14; 2.82), non-smoking habits $(\mathrm{OR}=0.46,95 \% \mathrm{CI}$ : 0.23 ; 0.92), lower psychological distress $(\mathrm{OR}=0.94,95 \% \mathrm{CI}$ : $0.91 ; 0.98)$, higher outcome expectations $(\mathrm{OR}=1.02,95 \%$ CI: $1.01 ; 1.04)$, and perceive more exercise barriers $(\mathrm{OR}=$ 1.05, 95 \% CI: 1.03; 1.07) than non-participants. The AUC for this model was 0.69 (95 \% CI: 0.64; 0.74). No significant associations were found between participation and treatment-related or physical characteristics.

\section{Correlates of adherence in $\mathrm{HI}$}

In $\mathrm{HI}$, higher self-efficacy was significantly associated with high session attendance (OR $=1.06,95 \% \mathrm{CI}: 1.03$; 1.09; $\mathrm{AUC}=0.75,95 \% \mathrm{CI}: 0.66 ; 0.84)$ and high compliance with endurance exercises $(\mathrm{OR}=1.05,95 \% \mathrm{CI}$ : 1.02; 1.07; AUC $=0.68,95 \%$ CI: 0.59; 0.77) (Table 5). Furthermore, less psychological distress $(\mathrm{OR}=0.87,95 \% \mathrm{CI}$ : 0.81 ; 0.94) was significantly correlated with high compliance with resistance exercises in $\mathrm{HI}$ (AUC $=0.69,95 \%$ CI: 0.60; 0.79). Demographic, treatment-related, physical and environmental characteristics were not significantly associated with exercise adherence in HI.

\section{Correlates of adherence in LMI}

In LMI, being a non-smoker (OR $=0.16,95 \% \mathrm{CI}$ : 0.03; 0.91) was significantly associated with high compliance with resistance exercises (Table 5), and higher BMI was significantly associated with high compliance with resistance exercises $(\mathrm{OR}=1.11,95 \% \mathrm{CI}: 1.00 ; 1.23)$ and endurance exercises (OR $=1.11,95 \%$ CI: 1.01; 1.21). Furthermore, breast cancer survivors were less likely to report high compliance with resistance exercises ( $\mathrm{OR}=3.25,95 \% \mathrm{CI}$ : 1.31; 8.02) and high compliance with endurance exercises $(\mathrm{OR}=2.94$, 95 \% CI: 1.38; 6.27) in LMI than survivors of other types of cancer. The AUC for the models of high compliance with resistance and endurance exercises were 0.69 (95\% CI: $0.60 ; 0.79)$ and 0.67 (95 \% CI: $0.58 ; 0.77)$, respectively. Treatment-related, psychosocial, physical and environmental characteristics were not significantly associated with exercise adherence in LMI.

\section{Discussion}

The current study identified important demographic, clinical, psychosocial, physical and environmental factors that may influence participation and exercise adherence, aiming to facilitate successful exercise participation among cancer survivors. We found that some demographic and psychosocial factors were significantly associated with exercise participation and adherence. Additionally, we found that psychosocial factors such as psychological distress and self-efficacy were more strongly associated with adherence to HI than LMI.

\section{(Non-) participation}

The current participation rates of $37 \%$ are in line with previous exercise trials among cancer survivors, reporting that $35-50 \%$ of the eligible patients participated [26, 27]. Our finding that patients with a high level of education were more likely to participate supports previous findings in cancer survivors during active cancer treatment [8]. 
Table 3 Baseline characteristics of (non-) participants

\begin{tabular}{|c|c|c|c|}
\hline & \multirow[t]{2}{*}{ Non-participants $(n=179)$} & \multicolumn{2}{|c|}{ Participants $(n=277)$} \\
\hline & & $\mathrm{HI}(n=139)$ & LMI $(n=138)$ \\
\hline \multicolumn{4}{|l|}{ Demographic } \\
\hline Age, mean $(S D)$ years & $55(10.6)$ & $54(10.7)$ & $53(11.4)$ \\
\hline Gender, $n(\%)$ male & $26(15)$ & $29(21)$ & $26(19)$ \\
\hline Marital status, $n(\%)$ having a partner & $150(84)$ & $112(81)$ & $120(87)$ \\
\hline Education, $n$ (\%) high & $43(25)$ & $52(38)$ & $53(39)$ \\
\hline Employment status at baseline, $n$ (\%) yes & $91(51)$ & $85(61)$ & $82(59)$ \\
\hline Smoking status at baseline, $n$ (\%) yes & $27(15)$ & $9(7)$ & $8(6)$ \\
\hline Sport history, $n(\%)$ yes & $100(57)$ & $72(52)$ & $83(61)$ \\
\hline \multicolumn{4}{|l|}{ Clinical } \\
\hline \multicolumn{4}{|l|}{ Cancer type, $n(\%)$} \\
\hline Breast & $120(67)$ & $92(66)$ & $89(65)$ \\
\hline Colon & $31(17)$ & $25(18)$ & $24(17)$ \\
\hline Ovarian & $6(3)$ & $8(6)$ & $4(3)$ \\
\hline Lymphoma & $16(9)$ & $10(7)$ & $16(12)$ \\
\hline Cervix & $4(2)$ & 0 & $4(3)$ \\
\hline Testis & $2(1)$ & $4(3)$ & $1(1)$ \\
\hline \multicolumn{4}{|l|}{ Stage of disease, $n(\%)$} \\
\hline Local & $123(69)$ & $103(74)$ & $84(61)$ \\
\hline Advanced & $55(31)$ & $36(26)$ & $54(39)$ \\
\hline \multicolumn{4}{|l|}{ Type of treatment, $n$ (\%) } \\
\hline Surgery & $161(90)$ & $127(91)$ & $123(89)$ \\
\hline Radiation therapy & $87(49)$ & $74(53)$ & $61(44)$ \\
\hline Immunotherapy & $33(18)$ & $23(17)$ & $36(26)$ \\
\hline Hormone therapy & $81(45)$ & $67(48)$ & $61(44)$ \\
\hline Comorbidities $\geq 2, n(\%)$ yes & $26(15)$ & $16(12)$ & $14(10)$ \\
\hline BMl in $\mathrm{kg} / \mathrm{m}^{2}$, mean (SD) & n.a. & $27.2(4.5)$ & $26.6(4.2)$ \\
\hline \multicolumn{4}{|l|}{ Psychosocial } \\
\hline General fatigue (MFI), mean (SD) ${ }^{a}$ & $12.3(4.4)$ & $12.8(3.8)$ & $12.9(4.2)$ \\
\hline Global HRQoL (QLQ-C30), mean (SD) ${ }^{b}$ & $70.9(18.2)$ & $71.3(16.2)$ & $73.1(16.1)$ \\
\hline Psychological distress (HADS), mean (SD) ${ }^{c}$ & $8.2(6.4)$ & $7.4(5.7)$ & $7.6(5.3)$ \\
\hline Attitude, mean (SD) & $83.8(21.2)$ & $85.2(22.3)$ & $87.3(18.8)$ \\
\hline Perceived barriers, mean (SD) & $23.1(12.4)$ & $28.6(12.3)$ & $25.8(12.0)$ \\
\hline Outcome expectations, mean (SD) & $71.8(17.8)$ & $75.0(15.7)$ & $76.0(13.7)$ \\
\hline Self-efficacy, mean (SD) & $64.8(17.9)$ & $59.9(16.6)$ & $61.1(16.4)$ \\
\hline Social support, mean (SD) & $79.3(21.1)$ & $81.9(20.6)$ & $81.0(20.1)$ \\
\hline \multicolumn{4}{|l|}{ Physical } \\
\hline Exercise stage, $n(\%)^{d}$ & $85(50)$ & $66(49)$ & $67(49)$ \\
\hline Self-reported PA & $115.6(91.3)$ & $96.7(69.0)$ & $106.2(83.1)$ \\
\hline \multicolumn{4}{|l|}{ Environmental } \\
\hline Travel distance to the exercise program (in kilometres), mean (SD) & n.a. & $7.3(6.1)$ & $6.5(4.8)$ \\
\hline
\end{tabular}


Table 3 Baseline characteristics of (non-) participants (Continued)

\begin{tabular}{|c|c|c|c|}
\hline \multicolumn{4}{|l|}{ Adherence } \\
\hline High session attendance, $n(\%)$ & - & $106(76)$ & $93(67)$ \\
\hline High compliance with resistance exercises, $n(\%)$ & - & $93(69)$ & $87(67)$ \\
\hline High compliance with endurance exercises, $n(\%)$ & - & $64(47)$ & $55(42)$ \\
\hline
\end{tabular}

Table 4 Odds ratios and their $95 \%$ confidence intervals as results from univariable and multivariable logistic regression analyses with participation as dependent variable and demographic, clinical, psychosocial and physical variables as independent variables

\begin{tabular}{|c|c|c|}
\hline & $\begin{array}{l}\text { Univariable, } \\
\text { OR }(95 \% \text { Cl) }\end{array}$ & $\begin{array}{l}\text { Multivariable, } \\
\text { OR (95\% Cl) }\end{array}$ \\
\hline \multicolumn{3}{|l|}{ Demographic } \\
\hline Age & $0.99(0.97 ; 1.00)$ & \\
\hline Gender & $0.69(0.41 ; 1.14)$ & \\
\hline Marital status & $1.00(0.60 ; 1.66)$ & \\
\hline Education & $1.89(1.24 ; 2.89)$ & $1.79(1.14 ; 2.82)$ \\
\hline Employment status & $1.47(1.01 ; 2.15)$ & \\
\hline Smoking status & $0.37(0.19 ; 0.70)$ & $0.46(0.23 ; 0.92)$ \\
\hline Sport history & $0.99(0.67 ; 1.44)$ & \\
\hline \multicolumn{3}{|l|}{ Clinical } \\
\hline Cancer type & $1.08(0.73 ; 1.61)$ & \\
\hline Stage of disease & $1.08(0.72 ; 1.61)$ & \\
\hline \multicolumn{3}{|l|}{ Type of treatment } \\
\hline Radiation therapy & $1.01(0.69 ; 1.46)$ & \\
\hline Immunotherapy & $1.20(0.75 ; 1.93)$ & \\
\hline Hormone therapy & $1.04(0.71 ; 1.52)$ & \\
\hline Comorbidities $(\geq 2)$ & $0.72(0.41 ; 1.25)$ & \\
\hline \multicolumn{3}{|l|}{ Psychosocial } \\
\hline General fatigue & $1.03(0.99 ; 1.08)$ & \\
\hline Global HRQoL & $1.01(0.99 ; 1.02)$ & \\
\hline Psychological distress & $0.98(0.95 ; 1.01)$ & $0.94(0.91 ; 0.98)$ \\
\hline Attitude & $1.01(1.00 ; 1.02)$ & \\
\hline Perceived barriers & $1.03(1.01 ; 1.05)$ & $1.05(1.03 ; 1.07)$ \\
\hline Outcome expectations & $1.02(1.00 ; 1.03)$ & $1.02(1.01 ; 1.04)$ \\
\hline Self-efficacy & $0.99(0.97 ; 1.00)$ & \\
\hline Social support & $1.01(1.00 ; 1.01)$ & \\
\hline \multicolumn{3}{|l|}{ Physical } \\
\hline Exercise stage & $0.97(0.66 ; 1.42)$ & \\
\hline Self-reported PA & $1.00(1.00 ; 1.00)$ & \\
\hline
\end{tabular}

Abbreviations: $p \leq 0.05$ in bold, OR odds ratio, $C l$ confidence interval, $H R Q o L$ Health-related quality of life, $P A$ physical activity
Accordingly, it has repeatedly been found in non-clinical populations that people who attained higher education are more likely to participate in health behavior change interventions [28]. Furthermore, the current study identified non-smoking as a significant correlate of participation. This was in contrast with a study in the Netherlands, who found no significant association between smoking and participation in an exercise trial during cancer treatment. Possibly, cancer survivors who chose to participate in an exercise trial after completion of primary cancer treatment might have experienced a 'teachable moment', or a need to change, during cancer treatment, including quitting smoking and participating in an exercise program [29]. Finally, we found that lower psychological distress, higher outcome expectations and experiencing more exercise barriers were significantly associated with participation. Our findings that patients with higher psychological distress and lower outcome expectations were more likely to decline participation, is in line with the previous study evaluating exercise programs in breast cancer survivors during chemotherapy [8]. Aiming to successfully target those subgroups of patients, previous studies suggested that clinical practice may benefit from behavior change strategies such as motivational interviewing [30]. Yet, further evidence is needed to determine which approaches are most efficacious among cancer survivors. Our finding that REACT participants reported more exercise barriers than non-participants seems paradoxical. However, it is possible that non-participants were not interested in exercise shortly after completion of primary cancer treatment and consequently perceived fewer barriers to obtain and maintain exercise, or that participants were more open to support from healthcare professionals in overcoming their exercise barriers, compared to the non-participants.

\section{Adherence}

In the HI and LMI groups, $76 \%$ and $67 \%$ of the participants showed high attendance rates, which is within the range reported by other exercise trials following cancer diagnosis [9]. However, comparing studies is limited by the scarcity of studies reporting on session attendance rates to supervised exercise after primary cancer treatment [9]. The compliance rates with the resistance and 
Table 5 Odds ratios and their $95 \%$ confidence intervals as results from univariable and multivariable logistic regression analyses with session attendance and compliance with the resistance and endurance exercises as dependent variables and demographic, clinical, psychosocial and physical variables as independent variables

\begin{tabular}{|c|c|c|c|c|c|c|c|c|c|c|c|c|}
\hline & \multicolumn{6}{|l|}{$\mathrm{HI}$} & \multicolumn{6}{|l|}{$\underline{L M I}$} \\
\hline & \multicolumn{2}{|c|}{ Session attendance } & \multicolumn{2}{|c|}{$\begin{array}{l}\text { Compliance with the } \\
\text { resistance exercises }\end{array}$} & \multicolumn{2}{|c|}{$\begin{array}{l}\text { Compliance with the } \\
\text { endurance exercises }\end{array}$} & \multicolumn{2}{|c|}{ Session attendance } & \multicolumn{2}{|c|}{$\begin{array}{l}\text { Compliance with the } \\
\text { resistance exercises }\end{array}$} & \multicolumn{2}{|c|}{$\begin{array}{l}\text { Compliance with the } \\
\text { endurance exercises }\end{array}$} \\
\hline & $\begin{array}{l}\text { Univariable, } \\
\text { OR }(95 \% \text { Cl) }\end{array}$ & $\begin{array}{l}\text { Multivariable, } \\
\text { OR (95\% Cl) }\end{array}$ & $\begin{array}{l}\text { Univariable, } \\
\text { OR (95\% Cl) }\end{array}$ & $\begin{array}{l}\text { Multivariable, } \\
\text { OR }(95 \% \mathrm{Cl})\end{array}$ & $\begin{array}{l}\text { Univariable, } \\
\text { OR (95\% Cl) }\end{array}$ & $\begin{array}{l}\text { Multivariable, } \\
\text { OR }(95 \% \mathrm{Cl})\end{array}$ & $\begin{array}{l}\text { Univariable, } \\
\text { OR ( } 95 \% \text { Cl) }\end{array}$ & $\begin{array}{l}\text { Multivariable, } \\
\text { OR }(95 \% \mathrm{Cl})\end{array}$ & $\begin{array}{l}\text { Univariable, } \\
\text { OR }(95 \% \text { Cl) }\end{array}$ & $\begin{array}{l}\text { Multivariable, } \\
\text { OR (95\% Cl) }\end{array}$ & $\begin{array}{l}\text { Univariable, } \\
\text { OR (95\% Cl) }\end{array}$ & $\begin{array}{l}\text { Multivariable, } \\
\text { OR }(95 \% \mathrm{Cl})\end{array}$ \\
\hline \multicolumn{13}{|l|}{ Demographic } \\
\hline Age & $\begin{array}{l}1.01 \\
(0.98 ; 1.05)\end{array}$ & & $\begin{array}{l}1.00 \\
(0.97 ; 1.03)\end{array}$ & & $\begin{array}{l}1.01 \\
(0.97 ; 1.04)\end{array}$ & & $\begin{array}{l}1.00 \\
(0.97 ; 1.04)\end{array}$ & & $\begin{array}{l}1.03 \\
(0.99 ; 1.06)\end{array}$ & & $\begin{array}{l}1.01 \\
(0.98 ; 1.05)\end{array}$ & \\
\hline Gender & $\begin{array}{l}0.62 \\
(0.22 ; 1.78)\end{array}$ & & $\begin{array}{l}0.51 \\
(0.19 ; 1.37)\end{array}$ & & $\begin{array}{l}0.97 \\
(0.42 ; 2.20)\end{array}$ & & $\begin{array}{l}0.71 \\
(0.27 ; 1.83)\end{array}$ & & $\begin{array}{l}0.45 \\
(0.16 ; 1.30)\end{array}$ & & $\begin{array}{l}0.41 \\
(0.17 ; 1.01)\end{array}$ & \\
\hline Marital status & $\begin{array}{l}1.15 \\
(0.44 ; 3.04)\end{array}$ & & $\begin{array}{l}1.22 \\
(0.49 ; 3.02)\end{array}$ & & $\begin{array}{l}1.29 \\
(0.54 ; 3.07)\end{array}$ & & $\begin{array}{l}0.70 \\
(0.23 ; 2.14)\end{array}$ & & $\begin{array}{l}0.64 \\
(0.19 ; 2.16)\end{array}$ & & $\begin{array}{l}0.40 \\
(0.14 ; 1.20)\end{array}$ & \\
\hline Education & $\begin{array}{l}1.29 \\
(0.56 ; 2.94)\end{array}$ & & $\begin{array}{l}1.84 \\
(0.84 ; 4.05)\end{array}$ & & $\begin{array}{l}1.67 \\
(0.83 ; 3.38)\end{array}$ & & $\begin{array}{l}0.66 \\
(0.32 ; 1.37)\end{array}$ & & $\begin{array}{l}0.49 \\
(0.23 ; 1.05)\end{array}$ & & $\begin{array}{l}0.45 \\
(0.21 ; 0.94)\end{array}$ & \\
\hline Employment status & $\begin{array}{l}1.66 \\
(0.75 ; 3.66)\end{array}$ & & $\begin{array}{l}0.96 \\
(0.45 ; 2.03)\end{array}$ & & $\begin{array}{l}1.38 \\
(0.69 ; 2.78)\end{array}$ & & $\begin{array}{l}0.84 \\
(0.41 ; 1.75)\end{array}$ & & $\begin{array}{l}0.43 \\
(0.19 ; 0.94)\end{array}$ & & $\begin{array}{l}0.67 \\
(0.33 ; 1.35)\end{array}$ & \\
\hline Smoking status & $\begin{array}{l}0.62 \\
(0.14 ; 2.64)\end{array}$ & & $\begin{array}{l}1.66 \\
(0.33 ; 8.42)\end{array}$ & & $\begin{array}{l}0.90 \\
(0.23 ; 3.52)\end{array}$ & & $\begin{array}{l}0.27 \\
(0.06 ; 1.19)\end{array}$ & & $\begin{array}{l}0.18 \\
(0.03 ; 0.97)\end{array}$ & $\begin{array}{l}0.16 \\
(0.03 ; 0.91)\end{array}$ & $\begin{array}{l}0.22 \\
(0.03 ; 1.87)\end{array}$ & \\
\hline Sport history & $\begin{array}{l}1.61 \\
(0.73 ; 3.55)\end{array}$ & & $\begin{array}{l}0.95 \\
(0.46 ; 1.98)\end{array}$ & & $\begin{array}{l}1.22 \\
(0.62 ; 2.41)\end{array}$ & & $\begin{array}{l}1.40 \\
(0.67 ; 2.91)\end{array}$ & & $\begin{array}{l}1.54 \\
(0.72 ; 3.28)\end{array}$ & & $\begin{array}{l}0.92 \\
(0.45 ; 1.89)\end{array}$ & \\
\hline \multicolumn{13}{|l|}{ Clinical } \\
\hline Cancer type & $\begin{array}{l}1.21 \\
(0.52 ; 2.81)\end{array}$ & & $\begin{array}{l}1.90 \\
(0.83 ; 4.35)\end{array}$ & & $\begin{array}{l}0.94 \\
(0.46 ; 1.93)\end{array}$ & & $\begin{array}{l}2.16 \\
(0.97 ; 4.80)\end{array}$ & & $\begin{array}{l}2.71 \\
(1.16 ; 6.36)\end{array}$ & $\begin{array}{l}3.25 \\
(1.31 ; 8.02)\end{array}$ & $\begin{array}{l}2.66 \\
(1.27 ; 5.56)\end{array}$ & $\begin{array}{l}2.94 \\
(1.38 ; 6.27)\end{array}$ \\
\hline Stage of disease & $\begin{array}{l}1.39 \\
(0.54 ; 3.56)\end{array}$ & & $\begin{array}{l}1.73 \\
(0.71 ; 4.22)\end{array}$ & & $\begin{array}{l}0.77 \\
(0.36 ; 1.69)\end{array}$ & & $\begin{array}{l}0.82 \\
(0.40 ; 1.69)\end{array}$ & & $\begin{array}{l}0.85 \\
(0.40 ; 1.82)\end{array}$ & & $\begin{array}{l}1.30 \\
(0.63 ; 2.66)\end{array}$ & \\
\hline \multicolumn{13}{|l|}{ Type of treatment } \\
\hline Radiation therapy & $\begin{array}{l}2.04 \\
(0.92 ; 4.54)\end{array}$ & & $\begin{array}{l}0.79 \\
(0.38 ; 1.65)\end{array}$ & & $\begin{array}{l}1.39 \\
(0.71 ; 2.76)\end{array}$ & & $\begin{array}{l}0.99 \\
(0.49 ; 2.04)\end{array}$ & & $\begin{array}{l}0.90 \\
(0.43 ; 1.88)\end{array}$ & & $\begin{array}{l}1.17 \\
(0.58 ; 2.37)\end{array}$ & \\
\hline Immunotherapy & $\begin{array}{l}0.67 \\
(0.25 ; 1.82)\end{array}$ & & $\begin{array}{l}1.05 \\
(0.40 ; 2.79)\end{array}$ & & $\begin{array}{l}1.96 \\
(0.78 ; 4.91)\end{array}$ & & $\begin{array}{l}0.58 \\
(0.26 ; 1.28)\end{array}$ & & $\begin{array}{l}0.85 \\
(0.37 ; 1.93)\end{array}$ & & $\begin{array}{l}1.11 \\
(0.50 ; 2.44)\end{array}$ & \\
\hline Hormone therapy & $\begin{array}{l}1.17 \\
(0.53 ; 2.58)\end{array}$ & & $\begin{array}{l}0.79 \\
(0.38 ; 1.64)\end{array}$ & & $\begin{array}{l}1.31 \\
(0.67 ; 2.59)\end{array}$ & & $\begin{array}{l}1.32 \\
(0.64 ; 2.72)\end{array}$ & & $\begin{array}{l}0.58 \\
(0.28 ; 1.23)\end{array}$ & & $\begin{array}{l}0.69 \\
(0.34 ; 1.41)\end{array}$ & \\
\hline Comorbidities & $\begin{array}{l}0.68 \\
(0.22 ; 2.12)\end{array}$ & & $\begin{array}{l}0.66 \\
(0.22 ; 1.99)\end{array}$ & & $\begin{array}{l}0.73 \\
(0.24 ; 2.17)\end{array}$ & & $\begin{array}{l}0.63 \\
(0.20 ; 1.96)\end{array}$ & & $\begin{array}{l}0.75 \\
(0.23 ; 2.48)\end{array}$ & & $\begin{array}{l}1.62 \\
(0.51 ; 5.18)\end{array}$ & \\
\hline BMI & $\begin{array}{l}0.93 \\
(0.86 ; 1.02)\end{array}$ & & $\begin{array}{l}0.99 \\
(0.91 ; 1.08)\end{array}$ & & $\begin{array}{l}0.94 \\
(0.87 ; 1.02)\end{array}$ & & $\begin{array}{l}1.05 \\
(0.96 ; 1.15)\end{array}$ & & $\begin{array}{l}1.10 \\
(0.96 ; 1.22)\end{array}$ & $\begin{array}{l}1.11 \\
(1.00 ; 1.23)\end{array}$ & $\begin{array}{l}1.09 \\
(1.00 ; 1.19)\end{array}$ & $\begin{array}{l}1.11 \\
(1.01 ; 1.21)\end{array}$ \\
\hline
\end{tabular}


Table 5 Odds ratios and their $95 \%$ confidence intervals as results from univariable and multivariable logistic regression analyses with session attendance and compliance with the resistance and endurance exercises as dependent variables and demographic, clinical, psychosocial and physical variables as independent variables (Continued)

\begin{tabular}{|c|c|c|c|c|c|c|c|c|c|}
\hline \multicolumn{10}{|l|}{ Psychosocial } \\
\hline General fatigue & $\begin{array}{l}0.92 \\
(0.83 ; 1.02)\end{array}$ & & $\begin{array}{l}0.92 \\
(0.83 ; 1.01)\end{array}$ & & $\begin{array}{l}0.97 \\
(0.89 ; 1.06)\end{array}$ & & $\begin{array}{l}1.00 \\
(0.92 ; 1.09)\end{array}$ & $\begin{array}{l}1.03 \\
(0.94 ; 1.13)\end{array}$ & $\begin{array}{l}1.05 \\
(0.96 ; 1.14)\end{array}$ \\
\hline Global HRQoL & $\begin{array}{l}1.01 \\
(0.99 ; 1.03)\end{array}$ & & $\begin{array}{l}1.02 \\
(1.00 ; 1.04)\end{array}$ & & $\begin{array}{l}1.01 \\
(0.98 ; 1.03)\end{array}$ & & $\begin{array}{l}1.00 \\
(0.98 ; 1.02)\end{array}$ & $\begin{array}{l}1.00 \\
(0.98 ; 1.02)\end{array}$ & $\begin{array}{l}1.01 \\
(0.99 ; 1.03)\end{array}$ \\
\hline $\begin{array}{l}\text { Psychological } \\
\text { distress }\end{array}$ & $\begin{array}{l}0.93 \\
(0.87 ; 0.99)\end{array}$ & & $\begin{array}{l}0.87 \\
(0.81 ; 0.94)\end{array}$ & $\begin{array}{l}0.87 \\
(0.81 ; 0.94)\end{array}$ & $\begin{array}{l}0.91 \\
(0.85 ; 0.98)\end{array}$ & & $\begin{array}{l}1.00 \\
(0.94 ; 1.07)\end{array}$ & $\begin{array}{l}1.01 \\
(0.94 ; 1.08)\end{array}$ & $\begin{array}{l}1.00 \\
(0.93 ; 1.07)\end{array}$ \\
\hline Attitude & $\begin{array}{l}1.03 \\
(1.01 ; 1.04)\end{array}$ & & $\begin{array}{l}1.02 \\
(1.01 ; 1.04)\end{array}$ & & $\begin{array}{l}1.02 \\
(1.00 ; 1.04)\end{array}$ & & $\begin{array}{l}1.01 \\
(0.99 ; 1.03)\end{array}$ & $\begin{array}{l}1.00 \\
(0.98 ; 1.02)\end{array}$ & $\begin{array}{l}1.01 \\
(0.99 ; 1.03)\end{array}$ \\
\hline Perceived barriers & $\begin{array}{l}0.96 \\
(0.92 ; 0.99)\end{array}$ & & $\begin{array}{l}0.97 \\
(0.94 ; 1.00)\end{array}$ & & $\begin{array}{l}0.98 \\
(0.95 ; 1.01)\end{array}$ & & $\begin{array}{l}0.99 \\
(0.96 ; 1.02)\end{array}$ & $\begin{array}{l}0.98 \\
(0.95 ; 1.01)\end{array}$ & $\begin{array}{l}0.98 \\
(0.95 ; 1.01)\end{array}$ \\
\hline $\begin{array}{l}\text { Outcome } \\
\text { expectations }\end{array}$ & $\begin{array}{l}1.01 \\
(0.99 ; 1.04)\end{array}$ & & $\begin{array}{l}1.00 \\
(0.98 ; 1.03)\end{array}$ & & $\begin{array}{l}1.01 \\
(0.99 ; 1.03)\end{array}$ & & $\begin{array}{l}1.00 \\
(0.98 ; 1.03)\end{array}$ & $\begin{array}{l}1.02 \\
(0.99 ; 1.05)\end{array}$ & $\begin{array}{l}1.00 \\
(0.98 ; 1.03)\end{array}$ \\
\hline Self-efficacy & $\begin{array}{l}1.06 \\
(1.03 ; 1.09)\end{array}$ & $\begin{array}{l}1.06 \\
(1.03 ; 1.09)\end{array}$ & $\begin{array}{l}1.02 \\
(1.00 ; 1.05)\end{array}$ & & $\begin{array}{l}1.05 \\
(1.02 ; 1.07)\end{array}$ & $\begin{array}{l}1.05 \\
(1.02 ; 1.07)\end{array}$ & $\begin{array}{l}1.00 \\
(0.98 ; 1.02)\end{array}$ & $\begin{array}{l}1.00 \\
(0.98 ; 1.03)\end{array}$ & $\begin{array}{l}1.01 \\
(0.99 ; 1.03)\end{array}$ \\
\hline Social support & $\begin{array}{l}1.00 \\
(0.98 ; 1.02)\end{array}$ & & $\begin{array}{l}1.00 \\
(0.99 ; 1.02)\end{array}$ & & $\begin{array}{l}1.00 \\
(0.98 ; 1.02)\end{array}$ & & $\begin{array}{l}1.00 \\
(0.98 ; 1.02)\end{array}$ & $\begin{array}{l}1.00 \\
(0.98 ; 1.02)\end{array}$ & $\begin{array}{l}1.01 \\
(0.99 ; 1.02)\end{array}$ \\
\hline \multicolumn{10}{|l|}{ Physical } \\
\hline Exercise stage & $\begin{array}{l}2.96 \\
(1.26 ; 6.93)\end{array}$ & & $\begin{array}{l}1.08 \\
(0.52 ; 2.26)\end{array}$ & & $\begin{array}{l}1.66 \\
(0.83 ; 3.33)\end{array}$ & & $\begin{array}{l}0.86 \\
(0.42 ; 1.77)\end{array}$ & $\begin{array}{l}1.23 \\
(0.58 ; 2.60)\end{array}$ & $\begin{array}{l}0.65 \\
(0.32 ; 1.32)\end{array}$ \\
\hline Self-reported PA & $\begin{array}{l}1.00 \\
(0.99 ; 1.01)\end{array}$ & & $\begin{array}{l}1.00 \\
(1.00 ; 1.01)\end{array}$ & & $\begin{array}{l}1.00 \\
(1.00 ; 1.01)\end{array}$ & & $\begin{array}{l}1.00 \\
(0.99 ; 1.00)\end{array}$ & $\begin{array}{l}1.00 \\
(0.99 ; 1.00)\end{array}$ & $\begin{array}{l}1.00 \\
(1.00 ; 1.00)\end{array}$ \\
\hline \multicolumn{10}{|l|}{ Environmental } \\
\hline $\begin{array}{l}\text { Travel distance to } \\
\text { the exercise program }\end{array}$ & $\begin{array}{l}1.03 \\
(0.96 ; 1.11)\end{array}$ & & $\begin{array}{l}0.95 \\
(0.89 ; 1.03)\end{array}$ & & $\begin{array}{l}0.99 \\
(0.92 ; 1.06)\end{array}$ & & $\begin{array}{l}1.00 \\
(0.94 ; 1.07)\end{array}$ & $\begin{array}{l}1.06 \\
(0.99 ; 1.15)\end{array}$ & $\begin{array}{l}1.02 \\
(0.96 ; 1.08)\end{array}$ \\
\hline
\end{tabular}

Abbreviations: $p \leq 0.05$ in bold, $O R$ odds ratio, $C I$ confidence interval, HRQoL Health-related quality of life, $B M I$ body mass index, $P A$ physical activity 
endurance exercises did not differ significantly between $\mathrm{HI}$ and LMI. This suggests that the exercise prescriptions were equally feasible to perform when the participants attended the session. Regarding exercise types, compliance rates with resistance exercises were higher than compliance rates with endurance exercises in both groups. This may suggest that resistance exercises are more feasible for cancer survivors than endurance exercises. However, it may also reflect a lower accuracy of defining the maximum workload by MSEC and HRR for the endurance exercises, compared to the 1-RM measurement for the resistance exercises. Although the steep ramp test is a short maximal exercise capacity test, which has proven to be a reliable and valid method to estimate cardiorespiratory fitness in cancer survivors [31], its anaerobic nature may have overestimated the workload for the endurance exercises. Comparably, the Karvonen formula including HRR is a commonly used method to calculate training workload for endurance exercises [32], however, someone's resting heart rate is prone to day-to-day fluctuations.

Psychosocial variables were significantly associated with high session attendance and high compliance with resistance and endurance exercises in HI, but not in LMI. This suggests that an individual's self-efficacy and distress levels are important characteristics while accomplishing a $\mathrm{HI}$ exercise program. Hence, including behavioral motivational strategies aiming to improve these psychosocial variables may support cancer survivors in achieving their exercise goals, especially for participants with less favorable scores in these variables to begin with. Participants with less favorable scores could also be recommended to start with LMI exercise, and -after gaining further confidence in exercising- the exercise intensity could gradually increase over time [33].

In LMI, only being a non-smoker or clinical factors were significantly associated with high compliance with the resistance or endurance exercises. Previous studies in nonclinical populations have suggested that health-related behaviors such as a physically active lifestyle and being a non-smoker tend to cluster [34]. This may explain why non-smokers had higher compliance rates. In contrast, the significant association between higher BMI and high compliance with resistance and endurance exercises seems counterintuitive but may indicate that participants with a lower BMI generally had better physical health and found the training intensity of the LMI exercise program is less challenging. A similar explanation could be suggested for breast cancer survivors; LMI exercise might have been too low for them compared to the other five cancer diagnosis with generally lower 5-year survival rates, contributing to lower compliance rates. Though, previous studies also report that breast cancer survivors are more likely to experience difficulties in accomplishing resistance and endurance exercises due to a limited range of motion in the shoulders after surgery [35], cardiorespiratory problems after radiation therapy [36] or joint stiffness as a result of hormone therapy [37]. Yet, in our data we found no significant associations between type of treatment and exercise adherence. Future insight in the role of cancer treatment in exercise adherence is warranted.

\section{Strengths and limitations}

To the best of our knowledge, the current study is the first study assessing correlates of participation in exercise after completion of primary cancer treatment, facilitated by an extensive non-responder questionnaire completed by 179 non-participants. In addition, we assessed factors associated with participants' exercise adherence taking into account both session attendance, as well as compliance to the prescribed exercises. We included large sample sizes, a relatively large number of potential demographic, clinical, psychosocial and physical correlates, allowing multivariable regression analyses. Yet, the following limitations should be taken into account. First, 301 of our non-participants (63\%) did not complete the extensive non-responder survey, which limits the generalizability of the current findings. Nevertheless, no significant differences in age, gender and cancer type were found between the participants of the one-time survey and the non-responders. Second, the discriminative ability of the models was moderate, ranging from 0.62 to 0.75 [38]. This indicates that there may be other variables that were not included in our study that are important to explain differences in participation and adherence rates among cancer survivors. For example, previous research showed that low socioeconomic status was negatively associated with adherence rates in cardiopulmonary rehabilitation [39] and may warrant further investigation among cancer survivors. Moreover, in general, studies that have investigated social and environmental correlates of participation and adherence rates among cancer survivors are scarce. Previous studies in the healthy population showed that social and environmental factors including peer support, physician influence, and access to facilities at flexible time points [40] were significantly associated with exercise participation. Therefore, future studies should examine whether social and environmental factors are associated with participation in and exercise adherence to an exercise program among cancer survivors. Finally, theory-based interventions have shown to be more effective in changing behavior than non-theory based interventions [41]. Since the current study showed significant associations of outcome expectations and self-efficacy with participation in or adherence to an exercise program, forthcoming studies might consider a role for behavioral theory such as social cognitive theory or self-determination theory [42], to facilitate a better understanding of exercise behavior in cancer survivors. 


\section{Conclusion}

This study showed that cancer survivors who attained a higher level of education, were non-smokers, perceived less psychological distress, had higher outcome expectations and perceived more exercise barriers were more likely to participate in a combined resistance and endurance exercise trial. This is worth acknowledging when promoting exercise participation as part of usual cancer care. Furthermore, the current study found several demographic, clinical and psychosocial factors to be significantly associated with exercise adherence in which, psychosocial factors, such as psychological distress and self-efficacy were more strongly associated with HI than LMI exercise. When offering $\mathrm{HI}$ exercise, it may therefore be recommended to screen these variables, and if needed, include additional behavioral motivational strategies or consider starting at a lower training intensity.

\section{Abbreviations \\ AUC: Area under the receiver operating characteristic curve; BMl: Body mass index; Cl: Confidence interval; EORTC QLQ C-30: European Organisation Research and Treatment of Cancer - Quality of Life Questionnaire C30; HADS: Hospital anxiety and depression scale; HI: High intensity; HRQOL: Health-related quality of life; LMI: Low-to-moderate intensity; MFI: Multidimensional fatigue inventory; OR: Odds ratio; PA: Physical activity; PASE: Physical Activity Scale for the Elderly Questionnaire; QoL: Quality of life; RCT: Randomized controlled trial; REACT: Resistance and endurance exercise after chemotherapy; WLC: Waiting list control}

\section{Acknowledgements}

The REACT study is part of the A-CaRe Program, http://www.a-care.org. The authors acknowledge the A-CaRe Clinical Research Group and thank all patients who participated in the trial. In addition, we thank the oncologists, nurses, sports physicians and their laboratory staff, rehabilitation specialists, and physical therapists for their support in conducting the trial. Furthermore, the authors would like to acknowledge Astrid Broersen, Eric Buytels, and Lars van Knippenberg for their contribution to the development of the exercise programs. We wish to thank Karen van der Weiden, Charlotte de Kruif, Joep van Kesteren, Julie Heeren and Viviana Groutars for their support in patient recruitment, data collection and/or assembly of data.

\section{Funding}

This work was supported by the Alpe d'HuZes/KWF Fund. The research grant is provided by the Dutch Cancer Society [Grant number ALPE 2009-4619]. Both funders had no role in study design, data collection, analyses, and interpretation presented in this manuscript nor in the decision of submission for publication.

\section{Availability of data and materials}

At present, raw data of the REACT study forms part of a PhD project, including current data on participation and adherence. As more papers will be generated from the REACT dataset, such as long-term and costeffectiveness of exercise after chemotherapy, we are unable to publish this dataset. Furthermore, the REACT dataset is included in the internationally-shared POLARIS database [43], and researchers who are interested to collaborate are invited to prepare a paper proposal.

\section{Authors' contributions}

$C K$ and $L M B$ designed the study and performed the statistical analyses. CK, $L W$, LB and LMB conducted the study, operationalized study outcomes and drafted the manuscript. WM, GS, MN, MC and JB, gave critical revision of the manuscript for important intellectual content. All authors read and approved the final manuscript, and take responsibility for the integrity of the data.

\section{Competing interests}

WM disclosures: shareholder-director of VU University Medical Center Amsterdam spin-off company Evalua Nederland B.V. and non-executive board-member of Arbo Unie B.V. Both companies operate in the Dutch occupational health care market. The authors declare that they have no competing interests.

\section{Consent for publication}

Not applicable.

\section{Ethics approval and consent to participate}

The study was approved by the Medical Ethics Committee of the VU University Medical Center (Amsterdam) [2011/240] and the local ethical boards of all participating hospitals, including Máxima Medical Center (Eindhoven and Veldhoven), Catharina Hospital (Eindhoven), Elkerliek Hospital (Helmond), St. Anna Hospital (Geldrop), VieCuri Medical Center (Venray and Venlo), Zuwe Hofpoort Hospital (Woerden), St. Antonius Hospital (Utrecht and Nieuwegein), Academic Medical Center (Amsterdam), and Erasmus MC University Medical Center (Rotterdam).

\section{Author details}

${ }^{1}$ Department of Public \& Occupational Health, and the EMGO Institute for Health and Care Research, VU University Medical Center, Amsterdam, The Netherlands. ${ }^{2}$ Department of Epidemiology and Biostatistics and the EMGO Institute for Health and Care Research, VU University Medical Center, De Boelelaan 1089a, 1081 HV Amsterdam, The Netherlands. ${ }^{3}$ Department of Sports Medicine, Máxima Medical Center, Veldhoven, The Netherlands. ${ }^{4}$ Department of Hematology, Radboud University Medical Center, Nijmegen, The Netherlands.

Received: 18 December 2015 Accepted: 26 August 2016

Published online: 09 September 2016

\section{References}

1. Jones LW, Liang Y, Pituskin EN, Battaglini CL, Scott JM, Hornsby WE, et al. Effect of exercise training on peak oxygen consumption in patients with cancer: a meta-analysis. Oncologist. 2011;16:112-20.

2. Cramp F, Byron-Daniel J. Exercise for the management of cancer-related fatigue in adults. Cochrane Database Syst Rev. 2012;11:CD006145.

3. Mishra SI, Schrerer RW, Geigle PM, Berlanstein DR, Topaloglu O, Gotay CC, et al. Exercise interventions on health-related quality of life for cancer survivors. Cochrane Database Syst Rev. 2012;15(8):CD007566.

4. Kalter J, Kampshoff CS, Chinapaw MJ, van MW, Galindo-Garre F, Schep G, et al. Mediators of Exercise Effects on HRQoL in Cancer Survivors after Chemotherapy. Med Sci Sports Exerc 2016. [Epub ahead of print]

5. Ballard-Barbash R, Friedenreich CM, Courneya KS, Siddiqi SM, McTiernan A, Alfano CM. Physical activity, biomarkers, and disease outcomes in cancer survivors: a systematic review. J Natl Cancer Inst. 2012;104:815-40.

6. Schmid D, Leitzmann MF. Cardiorespiratory fitness as predictor of cancer mortality: a systematic review and meta-analysis. Ann Oncol. 2014;26:272-8.

7. Gollhofer SM, Wiskemann J, Schmidt ME, Klassen O, Ulrich CM, Oelmann J, et al. Factors influencing participation in a randomized controlled resistance exercise intervention study in breast cancer patients during radiotherapy. BMC Cancer. 2015;15:186.

8. van Waart H, van Harten WH, Buffart LM, Sonke GS, Stuiver MM, Aaronson NK. Why do patients choose (not) to participate in an exercise trial during adjuvant chemotherapy for breast cancer? Psychooncology. 2015;25:964-70.

9. Kampshoff CS, Jansen F, van Mechelen W, May AM, Brug J, Chinapaw MJ, et al. Determinants of exercise adherence and maintenance among cancer survivors: a systematic review. Int J Behav Nutr Phys Act. 2014;11:80

10. Kampshoff CS, Buffart LM, Schep G, van Mechelen W, Brug J, Chinapaw MJ. Design of the Resistance and Endurance exercise After ChemoTherapy (REACT) study: a randomized controlled trial to evaluate the effectiveness and cost-effectiveness of exercise interventions after chemotherapy on physical fitness and fatigue. BMC Cancer. 2010;10:658.

11. Kampshoff CS, Chinapaw MJ, Brug J, Twisk JW, Schep G, Nijziel MR, et al. Randomized controlled trial of the effects of high intensity and low-tomoderate intensity exercise on physical fitness and fatigue in cancer survivors: results of the Resistance and Endurance exercise After ChemoTherapy (REACT) study. BMC Med. 2015;13:275.

12. Sabaté E. Adherence to long-term therapies: evidence for action. Geneva, Switzerland: World Health Organization; 2003. 
13. Kolt GS, McEvoy JF. Adherence to rehabilitation in patients with low back pain. Man Ther. 2003:8:110-6.

14. Courneya KS, Segal RJ, Gelmon K, Reid RD, Mackey JR, Friedenreich CM, et al. Predictors of supervised exercise adherence during breast cancer chemotherapy. Med Sci Sports Exerc. 2008;40:1180-7.

15. Valderas JM, Starfield B, Sibbald B, Salisbury C, Roland M. Defining comorbidity: implications for understanding health and health services. Ann Fam Med. 2009;7:357-63.

16. Chinapaw MJ, Buffart LM, van Mechelen W, Schep G, Aaronson NK, van Harten WH, et al. Alpe d'HuZes Cancer Rehabilitation (A-CaRe) Research: Four Randomized Controlled Exercise Trials and Economic Evaluations in Cancer Patients and Survivors. Int J Behav Med. 2012;19:143-56.

17. Smets EM, Garssen B, Bonke B, de Haes JC. The Multidimensional Fatigue Inventory (MFI) psychometric qualities of an instrument to assess fatigue. J Psychosom Res. 1995;39:315-25.

18. Aaronson NK, Ahmedzai S, Bergman B, Bullinger M, Cull A, Duez NJ, et al. The European Organization for Research and Treatment of Cancer QLQ-C30: a quality-of-life instrument for use in international clinical trials in oncology. J Natl Cancer Inst. 1993;85:365-76.

19. Spinhoven P, Ormel J, Sloekers PP, Kempen Gl, Speckens AE, van Hemert AM. A validation study of the Hospital Anxiety and Depression Scale (HADS) in different groups of Dutch subjects. Psychol Med. 1997;27:363-70.

20. Liu RD, Buffart LM, Kersten MJ, Spiering M, Brug J, van Mechelen W, et al. Psychometric properties of two physical activity questionnaires, the AQuAA and the PASE, in cancer patients. BMC Med Res Methodol. 2011;11:30.

21. Courneya KS, Friedenreich CM. Utility of the theory of planned behavior for understanding exercise during breast cancer treatment. Psychooncology. 1999:8:112-22.

22. van der Ploeg HP, van der Beek AJ, van der Woude LH, van Mechelen W. Physical activity for people with a disability: a conceptual model. Sports Med. 2004;34:639-49.

23. Marcus BH, Selby VC, Niaura RS, Rossi JS. Self-efficacy and the stages of exercise behavior change. Res Q Exerc Sport. 1992;63:60-6.

24. Sallis JF, Grossman RM, Pinski RB, Patterson TL, Nader PR. The development of scales to measure social support for diet and exercise behaviors. Prev Med. 1987; 16:825-36.

25. Prochaska JO, DiClemente CC. Stages and processes of self-change of smoking: toward an integrative model of change. J Consult Clin Psychol. 1983;51:390-5.

26. van Waart H, Stuiver MM, van Harten WH, Geleijn E, Kieffer JM, Buffart LM, et al. Effect of Low-Intensity Physical Activity and Moderate- to High-Intensity Physical Exercise During Adjuvant Chemotherapy on Physical Fitness, Fatigue, and Chemotherapy Completion Rates: Results of the PACES Randomized Clinical Trial. J Clin Oncol. 2015;33:1918-27.

27. Courneya KS, McKenzie DC, Mackey JR, Gelmon K, Friedenreich CM, Yasui Y, et al. Effects of exercise dose and type during breast cancer chemotherapy: multicenter randomized trial. J Natl Cancer Inst. 2013;105:1821-32.

28. Lakerveld J, ljzelenberg W, Van Tulder MW, Hellemans IM, Rauwerda JA, van Rossum AC, et al. Motives for (not) participating in a lifestyle intervention trial. BMC Med Res Methodol. 2008;8:17.

29. Flocke SA, Clark E, Antognoli E, Mason MJ, Lawson PJ, Smith S, et al. Teachable moments for health behavior change and intermediate patient outcomes. Patient Educ Couns. 2014;96:43-9.

30. Spencer JC, Wheeler SB. A systematic review of Motivational Interviewing interventions in cancer patients and survivors. Patient Educ Couns. 2016;99(7):1099-105.

31. De Backer I, Schep G, Hoogeveen A, Vreugdenhil G, Kester AD, van Breda E. Exercise testing and training in a cancer rehabilitation program: the advantage of the steep ramp test. Arch Phys Med Rehabil. 2007;88:610-6.

32. Karvonen J, Vuorimaa T. Heart rate and exercise intensity during sports activities. Pract Appl Sports Med. 1988;5:303-11.

33. van Weert E, Hoekstra-Weebers JE, Grol BM, Otter R, Arendzen JH, Postema K, et al. Physical functioning and quality of life after cancer rehabilitation. Int J Rehabil Res. 2004;27:27-35.

34. Busch V, Van Stel HF, Schrijvers AJ, de Leeuw JR. Clustering of health-related behaviors, health outcomes and demographics in Dutch adolescents: a cross-sectional study. BMC Public Health. 2013;13:1118.

35. Johansen S, Fossa K, Nesvold IL, Malinen E, Fossa SD. Arm and shoulder morbidity following surgery and radiotherapy for breast cancer. Acta Oncol. 2014;53:521-9.
36. Zagar TM, Cardinale DM, Marks LB. Breast cancer therapy-associated cardiovascular disease. Nat Rev Clin Oncol. 2015;13:172-84.

37. Crew KD, Greenlee H, Capodice J, Raptis G, Brafman L, Fuentes D, et al. Prevalence of joint symptoms in postmenopausal women taking aromatase inhibitors for early-stage breast cancer. J Clin Oncol. 2007;25:3877-83.

38. Hosmer DW, Lemeshow S. Applied logistic regression. 2nd ed. New York: Wiley; 2000.

39. Jackson L, Leclerc J, Erskine Y, Linden W. Getting the most out of cardiac rehabilitation: a review of referral and adherence predictors. Heart. 2005;91:10-4

40. Trost SG, Owen N, Bauman AE, Sallis JF, Brown W. Correlates of adults' participation in physical activity: review and update. Med Sci Sports Exerc. 2002;34:1996-2001.

41. Glanz K, Bishop DB. The role of behavioral science theory in development and implementation of public health interventions. Annu Rev Public Health. 2010;31:399-418.

42. Bandura A. Health promotion by social cognitive means. Health Educ Behav. 2004;31:143-64.

43. Buffart LM, Kalter J, Chinapaw MJ, Heymans MW, Aaronson NK, Courneya KS, et al. Predicting OptimaL cAncer Rehabllitation and Supportive care (POLARIS): rationale and design for meta-analyses of individual patient data of randomized controlled trials that evaluate the effect of physical activity and psychosocial interventions on health-related quality of life in cancer survivors. Syst Rev. 2013;2:75.

\section{Submit your next manuscript to BioMed Central and we will help you at every step:}

- We accept pre-submission inquiries

- Our selector tool helps you to find the most relevant journal

- We provide round the clock customer support

- Convenient online submission

- Thorough peer review

- Inclusion in PubMed and all major indexing services

- Maximum visibility for your research

Submit your manuscript at www.biomedcentral.com/submit 